\title{
EXPERIÊNCIAS DE ENSINO DA DANÇA EM CENÁRIOS NÃO ESCOLARES NO RIO DE JANEIRO DO SÉCULO XIX (DÉCADAS DE 1810-1850)
}

\author{
EXPERIENCES IN DANCE TEACHING IN NON-SCHOOL SETTINGS IN 19TH \\ CENTURY RIO DE JANEIRO (1810S-1850S)
}

EXPERIENCIAS DE ENSEÑANZA DE LA DANZA EN ESPACIOS NO ESCOLARES EN RIO DE JANEIRO DEL SIGLO XIX (DÉCADAS DE 1810 A 1850)

\section{Victor Andrade Melo*}

Palavras-chave
Dança.
História.
Educação.
Docentes.

Keywords

Dance.

History.

Education.

Teachers.

Palabras clave

Danza.

Historia.

Educación.

Docentes.
Resumo: Na primeira metade do século XIX, estruturaram-se no Rio de Janeiro diversas iniciativas relacionadas à dança, entabuladas em um contexto marcado por uma vida social cada vez mais dinâmica, que tinha como um dos indicadores a conformação de um mercado de entretenimentos. Este estudo tem por objetivo discutir, nesse quadro, experiências de ensino da dança em cenários não escolares. Como marcos temporais, adotaram-se os anos 1810, quando começaram a se delinear tais iniciativas, e a década de 1850, auge da popularidade da dança na cidade. Para alcance do objetivo, como fontes utilizaram-se periódicos fluminenses publicados no período em tela. Espera-se melhor compreender uma esfera importante de educação do corpo que tinha vários pontos de interface com outros âmbitos sociais, inclusive o escolar, sendo também uma faceta da história da cidade que merece ser desvendada.

Abstract: In the first half of the 19th century, several initiatives related to dance were carried out in Rio de Janeiro. They were organized in a context marked by increasingly dynamic social life, and one of its indicators was the emergence of an entertainment market. This study aims to discuss dance teaching experiences in non-school settings in that context. The timeframe covers the 1810s, when such initiatives started, and the 1850s, when dance reached its peak of popularity in the city. Sources included newspapers and magazines published in the period. We expect to increase our understanding of an important sphere of body education, which had several interface points with other social areas, including school, and was also an aspect of the city's history that deserves to be known.

Resumen: En la primera mitad del siglo XIX, se estructuraron en Rio de Janeiro varias iniciativas relacionadas con la danza, organizadas en un contexto marcado por una vida social cada vez más dinámica, que tenía como uno de sus indicadores la conformación de un mercado de entretenimiento. Este estudio tiene el objetivo de discutir, en ese marco, experiencias de enseñanza de la danza en escenarios no escolares. Como marcos temporales, fueron adoptados los años 1810, cuando comenzaron a tomar forma este tipo de iniciativas, y la década de 1850, auge de la popularidad de la danza en la ciudad. Como fuentes fueron utilizados periódicos publicados en el período. Se espera lograr una mejor comprensión de una importante esfera de la educación del cuerpo, que tenía varios puntos de interfaz con otros ámbitos sociales, incluso el escolar, siendo también una faceta de la historia de la ciudad que merece ser descubierta.
*Universidade Federal do Rio de Janeiro. Rio de Janeiro, RJ, Brasil. E-mail: victor.a.melo@uol.com.br

Recebido em: 02-07-2015 Aprovado em: 04-10-2015 (c) (1) (8) Licence 


\section{INTRODUÇÃO}

No dia 8 de março de 1808, o grande número de pessoas que assistiu, no Largo do Paço, o desembarque da família real portuguesa provavelmente não tinha noção das profundas mudanças pelas quais passaria o Rio de Janeiro nos anos seguintes, ainda que alguns já tivessem percebido que tal fato causaria interferências no seu cotidiano. Escoltados por britânicos, os monarcas tinham saído às pressas de Lisboa em função dos conflitos napoleônicos. Vieram junto alguns importantes personagens da Coroa e certos bens materiais, tendo em vista que o intuito era, mesmo que parecesse inusitado, tornar provisoriamente a antiga capital do Vice-Reinado do Brasil em sede do Império (NORTON, 2008, SCHULTZ, 2008).

Com a abertura dos portos e a instalação de instituições financeiras, fortaleceu-se a economia local, que já vinha se desenvolvendo, desde o século XVIII, em função da exportação de produtos diversos (CALDEIRA, 2011). Do ponto de vista político, aumentou o trânsito de ideias e o protagonismo de lideranças brasileiras estabelecidas na capital (NEVES, 2011). Muito perceptíveis foram as mudanças no âmbito cultural, dada a necessidade de transformar o Rio de Janeiro numa cidade que pudesse, de fato, ser reconhecida como sede do Império (SCHWARCZ, 2011).

Isso significou o entabular de uma série de intervenções no espaço urbano, mas também iniciativas que tinham em conta dotar a cidade de uma maior pujança no campo das artes, ações cujo ponto fulcral foi a vinda para o Brasil da Missão Artística Francesa. Uma das facetas relevantes desse processo foi a construção, no Largo do Rossio (atual Praça Tiradentes), do Real Teatro São João, inaugurado em 1813, renomeado em 1826, depois de um incêndio, para São Pedro de Alcântara ${ }^{1}$ (LIMA, 2000, MARZANO, 2010). No país independente, progressivamente se acentuaria essa intenção de fazer progredir a capital por meio de adesão a certos "parâmetros civilizatórios" que vinham da Europa (NEVES, 2011, SCHWARCZ, 2011).

No decorrer desse processo, a cidade foi ganhando uma nova dinâmica social, uma vida pública mais ativa, manifesta, inclusive e notadamente, na estruturação de um mercado de entretenimentos. Nesse cenário, uma das práticas que mais se desenvolveu e ganhou notoriedade foi a dança, aqui entendida não como aquelas que eram experienciadas de forma espontânea pelo grande conjunto da população, mas sim as que vinham do velho continente, sistematizadas e bailadas nas Cortes.

O próprio Real Teatro São João foi um dos pioneiros espaços de exibição dessa manifestação artística. Para que pudesse ser dinamizado, pelo menos até os anos 1850 recebeu artistas estrangeiros das mais distintas linguagens, que traziam para 0 Rio de Janeiro diversas novidades, sempre apreciadas numa cidade cuja elite desejava aprofundar seus laços com o exterior. A propósito, outro espaço de espetáculos que se tornou muito importante na cidade no período em tela, o circo (SILVA, 2007), também tinha a dança como uma de suas atrações.

Da mesma forma, a prática foi uma das principais manifestações a movimentar a vida de sociedades de recreio que se fundaram na cidade, cujo primeiro exemplo, ainda que em certa medida extemporâneo, foi a Assembleia Portuguesa, criada em 1815, por gente da elite que também estava envolvida com o funcionamento do Real Teatro São João (SILVA, 1978). 
Essas agremiações tornaram-se mais usuais a partir dos anos 1830. Foi nessa década que se criou uma das pioneiras sociedades dedicadas à dança, a "Bailes do Catete", cujos eventos atraíam famílias envolvidas com os antigos e novos negócios, personalidades influentes da cidade (CARDOSO, 2006, ZAMITH, 2011).

Com perfis semelhantes, contribuindo com o dinamismo da vida social da cidade, nos anos 1840 foram criadas mais agremiações: a Assembleia Estrangeira, localizada no Largo do Valderato, no bairro do Catete; o Cassino Fluminense, um dos mais importantes clubes do Rio de Janeiro do século XIX, local por onde passou grande parte das articulações políticas da nação (NEEDELL, 1993); a Sociedade Recreação Campestre, com sede no Campo da Aclamação (atual Campo de Santana), onde também se situava a Sociedade Amizade, que tinha a peculiaridade de oferecer algumas vagas para meninas pobres; a Sociedade de Baile Assembleia Fluminense, de vida curta, mas influente.

$\mathrm{Na}$ década de 1850, essa presença da dança no Rio de Janeiro se ampliou ainda mais, até mesmo devido à fundação de muitas sociedades dançantes. Além disso, a prática era oferecida constantemente em clubes sociais de caráter mais geral, bem como uma das mais apreciadas nos muitos salões, ocasiões em que membros das elites abriam as portas de suas residências para receber convidados (PINHO, 1942). Melo (2014) considera essa "febre" da dança como uma expressão das rápidas e profundas transformações pelas quais passou 0 município neutro da Corte.

Nesse contexto, em cenários não escolares, estruturaram-se iniciativas de ensino da dança, provavelmente as pioneiras relacionadas a uma prática corporal institucionalizada ${ }^{2}$, implementadas na cidade e no país. Por vários motivos nos interessa melhor compreender essas experiências. Primeiro, por tratar-se de uma esfera ligada à educação do corpo de importância em determinado momento. Segundo, por haver vários pontos de interface entre esse e outros âmbitos sociais, inclusive a escola, onde a dança também estava começando a ser oferecida; os mestres, de fato, atuavam simultaneamente em diferentes espaços. Por fim, por se tratar de uma faceta da história do Rio de Janeiro que merece ser desvendada.

Este estudo, portanto, tem por objetivo discutir essas experiências de ensino da dança em cenários não escolares no Rio de Janeiro do século XIX. Como marcos temporais, adotaram-se os anos 1810, quando começaram a se delinear tais iniciativas, e a década de 1850, auge da popularidade da prática na cidade.

Para alcance do objetivo, como fontes utilizaram-se periódicos fluminenses publicados no período em tela. Boa parte das informações trabalhadas diz respeito a anúncios das iniciativas, mas também foram analisados posicionamentos de cronistas. De toda forma, adotou-se uma operação similar: tratar o material não como expressão da verdade absoluta, mas sim como representações consideradas a partir de sua materialidade.

\section{ENSINANDO A DANÇAR}

Luiz Lacombe, professor de dança, ultimamente chegado ao Rio de Janeiro, tem a honra de anunciar a todas as pessoas civilizadas desta cidade que ele se propõe a ensinar todas as qualidades de danças próprias da sociedade; todas as pessoas que quiserem fazer a honra de tomar as suas lições o poderão procurar na rua do Ouvidor, n. 82, 3ํandar (GAZETA..., 1811, p. 6).

2 Aqui trabalho com o conceito de Melo (2010). 
Em 1811, assim Luiz Lacombe apresentou seus serviços, provavelmente o primeiro anúncio público de aulas de dança oferecidas no Rio de Janeiro. O personagem chegara à cidade nesse mesmo ano, acompanhando Marianna Scaramelli, sua esposa cantora que integrava a comitiva de Marcos Portugal, notório músico português que fora convocado por $D$. João para dinamizar a cena artística fluminense. No futuro, seria um dos principais responsáveis pela programação do Real Teatro São João, onde, a propósito, Lacombe também atuaria como bailarino e coreógrafo (ZAMONER, 2013).

$\mathrm{Na}$ verdade, havia na comitiva de Marcos Portugal outro mestre de dança, o italiano Pedro Colonna (CAVALCANTI, 2004), que já atuava, em Lisboa, na preparação de espetáculos e ministrando lições para a família real e para os alunos do importante Real Colégio dos Nobres. Todavia, quem se destacou mesmo naquelas primeiras décadas foi Lacombe e seus irmãos, Luiz Junior, Lourenço e José Manuel, que já vieram para o Brasil tendo em vista trabalhar como bailarinos e instrutores de dança (PINHO, 1942)33.

O número de iniciativas entabuladas pela família Lacombe é um indicador de que rapidamente gestou-se um mercado ao redor da dança ${ }^{4}$. A propósito, outros bailarinos se ofereceram como docentes. Em 1814, Lourenço Alberti apresentou suas credenciais ("mestre de dança estabelecido em Lisboa há muitos anos") e seus serviços, lições oferecidas na rua da Quitanda (GAZETA... 1814, p. 8).

$\mathrm{Na}$ década seguinte, o perfil dos mestres permaneceu semelhante. Além dos onipresentes Lacombe, em 1822 outro bailarino do Real Teatro São João, José Nazari, abriu uma sala na região central da cidade, na rua do Sacramento. Oferecia lições três vezes por semana - às segundas, quartas e sextas - das 19 às 22 horas (DIÁRIO..., 1823a, p. 11). Posteriormente, passou a lecionar todos os dias, com aulas de duas horas, cada aluno fazendo três sessões semanais (DIÁRIO..., 1823b, p. 51). Trata-se de mais um indicador de que não parava de crescer 0 interesse pela prática.

Por que esses bailarinos atuavam como docentes? Observamos que Pedro Colonna, ainda nos anos 1810, constantemente reclamava que recebia menos do que Marcos Portugal, solicitando equiparação de salários (MALERBA, 2008). Não é absurdo sugerir que os envolvidos encaravam essa oferta de lições como uma forma de complementar os vencimentos. Além disso, as aulas permitiam um contato maior com setores influentes da cidade (os que contratavam os serviços), sempre uma possibilidade de conseguir algum benefício em uma sociedade muito hierárquica e segmentada.

A crer no que sugere Ossona (1988), esse era um perfil também comum no continente europeu, ocupando os mestres, como os artistas, um curioso espaço intermediário na organização social - frequentavam o mundo das elites, mas não de forma plena, até mesmo porque não dispunham do capital econômico e simbólico para tal (não possuíam nem dinheiro e bens nem títulos nobiliárquicos ou laços familiares).

Além disso, a oferta de aulas poderia ser uma forma de dar sequência à carreira quando, por motivos diversos, inclusive a idade mais avançada, se reduzissem as possibilidades de participação nos espetáculos. Em 1822, Lourenço Lacombe anunciou que estava se despedindo

3 Vale citar que Nireu Cavalcanti (2004) identificou que houve um mestre de dança no Rio de Janeiro do século XVIII, Felipe Neri de Almeida, lisboeta que chegou à cidade, em 1768, com 22 anos. Além de fugir ao recorte desse estudo, até o momento não foi possível encontrar mais informações sobre esse personagem. 
do Teatro São João, passando a se dedicar a oferecer lições particulares na residência dos interessados (DIÁRIO..., 1822, p. 51). Desde o ano anterior, ele e seu irmão Luiz Júnior já faziam o mesmo na própria casa, localizada na rua do Conde (GAZETA..., 1821, p. 4). Curiosamente os horários e dias eram os mesmos do já citado José Nazari.

Poder-se-ia pensar que os Lacombe e Nazari se tornaram concorrentes. Todavia, em setembro de 1823, percebe-se que Lourenço passou a oferecer suas aulas na "soberba sala de dança" (DIÁRIO..., 1823c, p. 48) onde antes atuava o segundo, sobre o qual não encontramos mais notícias. Futuramente haveria inclusive uma articulação entre os horários dos Lacombe, um ensinando às segundas, quartas e sextas, enquanto o outro lecionava às terças, quintas e sábados (DIÁRIO..., 1829, p. 55).

Dado o volume de interessados, mais duas salas foram abertas posteriormente pela família. José Manuel Lacombe inovou ao dividir um desses espaços, localizado na rua do Ouvidor, com o professor de línguas Antonio Alves Branco Muniz Barreto. O mesmo fez ao se articular com a iniciativa de João Pedro de Souza Oliveira, que ministrava todas as matérias escolares. Como se pode ver, os locais utilizados para as lições foram bastante diversos.

Rivalidade entre mestres de dança houve mesmo entre Lourenço Lacombe e Miguel Vaccani Filho, outro que ofereceu seus serviços a partir de 1824 (CLAMOR..., 1824, p. 4). 0 problema se deu em função de apresentações no teatro e se manifestou na troca de acusações pelos jornais e por panfletos espalhados pela cidade. Como pano de fundo, se encontrava 0 fato de que o segundo questionava a qualidade artística da família do primeiro, inclusive a falta de trajetória no continente europeu. Mais do que vaidades artísticas, que certamente existiam, havia disputas pelo mercado e por maior projeção numa sociedade cuja elite não era lá tão grande.

Tendo em vista o acirramento das disputas, um dos aspectos que passou a ser mais mobilizado foi a qualidade e eficiência do ensino. Um dos que pioneiramente usou essa estratégia foi Felipe Aime, outro bailarino do Teatro São Pedro de Alcântara que oferecia aulas nas residências dos interessados e na sua casa da rua do Ouvidor. Ele prometia ensinar "senhores e senhoras, meninos e meninas", com "método fácil e brevidade" (DIÁRIO..., 1828a, p. 79).

No que tange à busca de inovações, deve-se destacar um casal que durante décadas ensinou a dança na cidade, José Maria e Carolina Toussaint, parte de um movimento de artistas que houve entre o Rio de Janeiro e Buenos Aires (LANGE, 1977), no qual também circulou outro importante professor que atuou na capital, Felipe Catton.

Por esse mesmo aspecto, tornaram-se também famosos um sobrinho de José Maria e sua esposa, Julio e Adéle Toussaint-Samson. Ele atuou como bailarino e coreógrafo, mas se destacou mesmo por seus serviços de mestre; foi inclusive o responsável pelo ensino da prática para a família real ${ }^{5}$ e no prestigioso Colégio Pedro II. Já ela destacou-se não só pelas aulas de dança e de línguas, como também por ser uma mulher à frente de seu tempo, que deixou registros importantes sobre o Rio de Janeiro ${ }^{6}$. Ambos decidiram vir ao Brasil em função do momento difícil que passavam na França, mas também por vislumbrar que, dado o interesse geral, se podia ganhar a vida e até fazer fortuna na Corte como professores de dança.

5 Lourenço Lacombe já desempenhara antes a mesma função, tendo sido até mesmo mestre de D. Pedro II.

6 Para uma resenha do livro que escreveu contando suas experiências no Rio de Janeiro, Uma parisiense no Brasil, ver Leite (2004). Nessa obra, muitos e interessantes foram os comentários sobre a dança. 
Todos esses artistas/mestres chegaram ao Rio de Janeiro nos últimos anos da década de 1840 e apresentaram à cidade novas formas de dançar, como a polca e o schottisch (ZAMITH, 2011). Ainda mais, lecionavam algo semelhante a certas coreografias apresentadas nos teatros. Vejamos um anúncio: "Felipe Catton, dançarino do Teatro, tem a honra de participar ao respeitável público que de hoje em diante dará lições de dança de todas as qualidades, principalmente espanhola, e igualmente uma gaivota composta por ele" (DIÁRIO..., 1831, p. 22). Em outra ocasião foi mais explícito no tocante aos conteúdos: "todas as danças de costume e os mais bonitos boleros de sala, minuetes e minuetes del Montonero" (DIÁRIO..., 1840, p. 4).

Luiz Lourenço Júnior, além de quadrilhas, valsas e mazurcas - primeiros estilos ensinados na cidade -, já lecionava um largo espectro de formas de bailar, "contradanças francesas, inglesas e espanholas, e todas as danças particulares de sala" (DIÁRIO..., 1833, p. 43). Mas os novos mestres incrementaram ainda mais intensamente essa variedade.

Felipe e Carolina Catton sugeriam que suas aulas abordavam "tanto o estilo antigo como o moderno" (DIÁRIO..., 1843, p. 4), isto é, tanto as danças já conhecidas, como valsas e mazurcas, como as que traziam como novidade, como a polca e o schottisch, bem como misturas de danças e algumas nacionais. Também Felipe Aime, um dos que mais anunciava inovações, sugeriu que suas lições não se restringiam às formas europeias de bailar, também ensinando as brasileiras. Teria lecionado estilos como o lundu? Não parece impossível.

Lembremos que o lundu existia desde o século XVIII e em meados do século XIX se tornou bem difundido, inclusive nos bailes das elites, na esteira do crescimento de um mercado de entretenimentos. Percebia-se um diálogo entre diferentes tradições culturais, no âmbito tanto da música (LEME, 2006) como da dança ${ }^{7}$. Essas ocorrências são exemplos de como, a despeito de tornar-se progressivamente explícita a influência europeia no Rio de Janeiro do século XIX, houve sim movimentos de reelaboração que acabaram por constituir uma peculiaridade cultural.

A questão dos métodos passou a ser mais difundida também por meio de material impresso. Melo (2014) sugeriu que, em 1854, foi lançado um primeiro manual da prática no país, Arte da dança de sociedade, editado pela Laemmert, dedicado ao ensino da valsa, da polca, da schottisch e da redowa. Na verdade, alguns anos antes já se vendia na cidade o Tratado dos princípios fundamentais da dança, no qual se apresentavam "os preceitos não só para o bem dançar, mas para andar, saudar e fazer airosamente as cerimônias" (O DESPERTADOR, 1840, p. 4). No decorrer da segunda metade do XIX, outros livros semelhantes foram publicados no Rio de Janeiro.

Passaram também a ser publicados mais folhetos com a descrição de coreografias, material usado para o ensino da dança. Um exemplo é "The Lancers", apresentada como uma quadrilha dançada num baile dedicado à Rainha Vitória da Inglaterra. Segundo o anúncio, tratava-se de "uma nova teoria para se dançar", recomendada para os mestres que querem lecionar novas combinações (DIÁRIO..., 1857a, p. 4).

Outro exemplo se observa quando "os sucessores de P. Lafore", em 1857, publicaram o "Cotilhão, com a explicação desta dança em português, oito lindas gravuras e música apropriada" (DIÁRIO..., 1857b, p. 1). 0 anúncio informou ainda que o estilo (marcado pela participação de muitos pares e distribuição de brindes, normalmente encerrando um baile) fora trazido ao Rio de Janeiro "pelo Sr. Toussaint, distinto professor". 
A propósito, uma mudança importante começou a ocorrer no que tange ao perfil dos mestres. Se antes todos eram bailarinos e coreógrafos, a partir de meados do século surgem docentes que não tinham essa experiência nos teatros, entre eles João José da Rocha, José Lourenço de Paiva e Francisco de Paula Paiva, que também ofereceram seus serviços pelos jornais e depois se tornaram professores do Colégio Pedro II.

Não conseguimos, contudo, até esse momento, obter mais informações sobre esses personagens. Como teriam resolvido se dedicar ao ensino da dança? Por que chegaram a lograr certo reconhecimento, a ponto de atuarem em uma instituição tão importante? Isso teria relação com seus laços familiares? Trata-se de questões que necessitam de mais investigações para serem respondidas.

Com tantos mestres oferecendo seus serviços pela cidade, uma pergunta se impõe: haveria tantos interessados assim? Pela longa trajetória de alguns, aparentemente sim. Mais ainda, é interessante identificar que muitos foram os pedidos de docentes publicados nos jornais: "Pretende-se tratar com um professor de dança para ensinar uma menina; quem estiver nessas circunstâncias dirija-se à praia de D. Manoel, n. 35, que achará com quem tratar" (DIÁRIO..., 1826, p. 51).

Alguns desses anúncios demonstram que havia mesmo interesse em mestres específicos (devemos ter em conta que os jornais eram um importante instrumento de contato naquele momento): "Na rua do Príncipe do Catete, existe uma pessoa que deseja ser discípula do Sr. professor de dança Felipe Aime, por cujo motivo deseja saber por esta mesma folha quanto pretende levar por cada mês (dando condução ou sem ela)" (DIÁRIO..., 1828b, p. 51).

Além disso, como vimos na introdução, havia muitos espaços distintos para os mestres atuarem: salas, residências próprias ou dos interessados, clubes sociais, sociedades dançantes, escolas. Com tal dinâmica, não surpreende que o próprio Almanak Lammert importante veículo de divulgação da vida social, política e econômica da Corte -, tenha aberto cada vez mais espaço para a divulgação dos nomes desses docentes.

Esse conjunto de oportunidades chegou a atrair personagens importantes do mundo internacional da dança, como Henry Cellarins, que desde 1826 oferecia aulas na sua residência à rua do Ouvidor. Reconhecido na Europa por sua atuação, foi autor de importantes livros dedicados ao tema e introdutor de uma variedade da valsa nos salões do velho continente (JOSÉ, 2005).

Outro que procurou fazer uso de suas credenciais, "discípulo da Academia Real de Música de Paris", para durante um tempo oferecer seus serviços foi Roman. Ele sequer parece ter constituído uma residência fixa, lecionando no próprio local onde se hospedou, o Hotel de França (um dos mais importantes da ocasião, localizado na rua do Ouvidor) (DIÁRIO..., 1827, p. 39).

Pode-se dizer que uma das tendências foi a maior estruturação das iniciativas. Inicialmente pode-se observar a transição de uma estrutura doméstica para um espaço público destinado às aulas, as salas de dança. Em 1844, J. A. Portugal informou que, além de ministrar as lições em escolas e casas dos interessados, pretendia abrir um "colégio de dança" (DIÁRIO..., 1844, p. 4). Na prática, o funcionamento era similar ao das salas, mas é digno de registro a explicitude da ideia de ensino. 
Dois anos depois, em 1846, foi criado o Conservatório de Dança e Música, localizado no Campo da Aclamação. Graças ao sucesso da iniciativa, no mesmo ano foi aberta uma filial na rua da Quitanda (DIÁRIO..., 1846, p. 4). Tendo como proprietário e mestre o italiano Francisco York, dançarino e coreógrafo dos teatros da cidade, na instituição também atuavam como professores os notáveis músicos Francisco Motta, José Joaquim dos Reis, Lino José Nunes e Alexandre Magallar. Além desses, ministrava aulas de dança outro bailarino notável, José De-Vecchy.

Esse estabelecimento era aparentemente muito bem organizado, dispondo de três salas para as atividades docentes, duas destinadas às aulas e uma para descanso. Uma delas tinha saletas para apoio das classes. Além de gabinetes para professores, havia um banheiro para as senhoras e um vestiário para troca de roupas (DIÁRIO..., 1846b, p. 4).

Essa edificação se localizava dentro de um grande parque com um jardim bem arborizado e florido, com iluminação para funcionamento noturno, onde eram oferecidos jogos diversos (galé, chinês, de bolas, tiro de pistola, arco e flecha, mesas para xadrez, dominó, damas e gamão, entre outros). No centro, havia um coreto onde se exibiam bandas de música e se apresentavam coreografias diversas. Logo esse pequeno teatro passou a ter atividade constante, nos jornais anunciado como Tivoly. Havia ainda um "botequim com refrescos e comidas" (DIÁRIO..., 1846b, p. 4). O preço da entrada era o comum à maior parte de entretenimentos da época, $1 \$ 000$ (MELO, PERES, 2014).

Como se pode ver, mais do que um espaço para ensino, tratava-se de um complexo de diversões, bem no espírito da sociedade fluminense daquele momento. Percebe-se que alguns dos discípulos dos mestres de dança se apresentavam no coreto/teatro, o que pode significar apenas mais um estímulo para os que somente desejavam aprender as danças, mas também uma possibilidade para os que queriam aprender 0 ofício.

Se fosse um espaço somente procurado por gente das elites, seria mais difícil visualizar essa segunda opção, mas tendo em conta que também frequentavam o Conservatório pessoas de setores médios e mesmo populares (York oferecia gratuidades para alguns alunos que demonstravam talento e não podiam pagar), essa já se torna uma possibilidade plausível. De toda forma, a profissionalização não parecia ser o intuito central do estabelecimento (destinado mesmo a oferecer aulas livres e diversões para os interessados). Tratava-se, a propósito, de uma iniciativa distinta, do ponto de vista institucional, à da criação do Conservatório de Música (AUGUSTO, 2010).

Em 1851, surgiu uma iniciativa claramente destinada a formar profissionais: "A comissão diretora do Teatro de São Pedro de Alcântara acaba de estabelecer uma escola de dança e outra de canto, para ter figurantes e coristas sem dependência de mandá-los buscar à Itália" (DIÁRIO..., 1851, p. 3). O cronista do Diário do Rio de Janeiro louvou a iniciativa, mas sugeriu que para dar certo deveria contar com mais investimentos governamentais.

A intenção era eliminar a necessidade de contratar estrangeiros, caminhando para desenvolver um corpo técnico nacional. Com intuito semelhante, no ano seguinte, "o sr. Desembargador Miranda" criou, no Teatro Provisório, aulas de música e dança, essas ministradas por Francisco York, "afim de formar bons discípulos para a companhia lírica e corpo de baile" (CORREIO..., 1852, p. 1). Os alunos e alunas, selecionados em concurso público, deveriam ter entre 10 e 15 anos. As lições eram diárias, das 9 às 11 horas. 
Um novo campo de atuação se abria para os mestres. Mais do que ensinar bailarinos amadores, tratava-se também de formar profissionais, outra faceta do fascinante mundo da dança naquela movimentada sociedade fluminense da década de 1850.

\section{CONCLUSÃO}

"Entre todos os divertimentos da gente moça, nenhum há com que ela mais folgue do que a dança, a que por isso chamaram nossos antigos de 'folias'; porém, meus filhos, este mesmo prazer não deixa de ter seus dissabores para os homens polidos" (ROQUETE, 1997, p. 147): assim começa o capítulo dedicado aos bailes do Código de Bom-Tom, um manual de conduta que se tornou popular no Rio de Janeiro de meados do século XIX (SCHWARCZ, 1997).

A presença da dança numa publicação dessa natureza não era despropositada. Numa cidade que passava por rápidas mudanças, na qual a cena pública tornava-se cada vez mais dinâmica, sentia-se a necessidade de regular os comportamentos. No caso da dança, havia ainda uma tensão aparente: homens e mulheres, em função da própria natureza da modalidade, desfrutavam de uma proximidade corporal muito grande para os padrões da época.

Nesse sentido, entende-se bem a vulgarização de experiências de ensino da dança no Rio de Janeiro do período estudado. Havia uma necessidade óbvia, a de aprender a bailar determinados estilos que não eram conhecidos e que passaram a ser valorizados em função do cenário contextual. 0 domínio desses códigos era um passaporte para se frequentar espaços nos quais se forjava a elite nacional do país recém-independente. Mais do que isso, havia que se aprender comportamentos, procedimentos e limites sem os quais poderiam fracassar essas iniciativas.

Logo, também se delineava o que para alguns não poderia ser considerado como dança, aquilo que deveria ser repelido, especialmente os estilos mais populares, considerados em muitas ocasiões lascivos. Não surpreende que muitas tenham sido as iniciativas de restringir essas outras formas de bailar, bem como de controlar as agremiações e locais menos elitistas onde também se experienciava a prática (MELO, 2014).

Isso era também necessário porque o novo hábito não gozou de imediata aceitabilidade em todos os setores. Para alguns, parecia uma licenciosidade inaceitável. As críticas mais contundentes vinham daqueles que defendiam que a religião deveria determinar os rumos sociais. Para esses, era ainda mais incômodo quando as atividades dançantes se chocavam com certos preceitos, como ironiza um cronista:

Os bailes na Quaresma, principalmente em vésperas de Domingo de Ramos e na Quarta-feira de Trevas, são muito edificantes às famílias e de sumo interesse à religião do Império: ambos os sexos ficam predispostos para preferir a dança à penitência, à gula, ao jejum; e é grave o exemplo para se transmitir à posteridade! Viva Epicuro! (O SETE..., 1837, p. 4).

A partir de meados do século, todavia, quando se intensifica a dinâmica social, inclusive devido à ação dos mestres que trouxeram para a cidade novas formas de dançar, percebe-se também sendo ensinados alguns estilos nacionais, talvez até os mais populares, mesmo porque já estavam a ser bailados inclusive em algumas iniciativas das elites. Na verdade, nesse momento já se delineara uma maior aceitabilidade da prática, mobilizada que foi no âmbito das novas preocupações em voga, especialmente no que tange às questões ligadas a saúde e higiene. 
No Diário do Rio de Janeiro, num artigo não assinado intitulado "Higiene Popular", se defendeu que entre os "exercícios de movimento próprio talvez se não conheça outro mais útil do que a dança, pelo seu duplicado influxo na constituição física e nos sentidos" (DIÁRIO..., 1840b, p. 1). Por isso, para o autor, os locais de baile deveriam ser considerados como "estabelecimentos de suma utilidade para a saúde pública". De toda forma, ressaltaramse os riscos que existiam em função da "reunião de pessoas desconhecidas umas às outras, e sobretudo a dos dois sexos". Mesmo com avanços, as preocupações com o pudor sempre permaneceriam.

Enfim, essas pioneiras experiências de ensino de uma prática corporal institucionalizada estavam plenamente relacionadas às novas necessidades sociais, as mesmas que, no futuro, gerariam uma maior aceitabilidade para outras práticas corporais que, no período estudado, já estavam ganhando popularidade, especialmente a ginástica e o esporte.

\section{REFERÊNCIAS}

AUGUSTO, Antonio. A civilização como missão: o Conservatório de Música no Império do Brasil.

Revista Brasileira de Música, Rio de Janeiro, v. 23, n. 1, p. 67-91, 2010.

CALDEIRA, Jorge. O processo econômico. In: SILVA, Alberto da Costa (Coord.). História do Brasil Nação (1808-2010). Rio de Janeiro: Objetiva, 2011. v. 1: Crise colonial e independência (1808-1830). p. $161-204$.

CARDOSO Lino de Almeida. 0 som e o soberano: uma história da depressão musical carioca pósAbdicação (1831-1843) e de seus antecedentes. Tese (Doutorado em História Social) - Faculdade de Filosofia, Letras e Ciências Humanas, Universidade de São Paulo, São Paulo, 2006.

CAVALCANTI, Nireu. Crônicas históricas do Rio colonial. Rio de Janeiro: Civilização Brasileira, 2004.

CLAMOR Nacional, 22 set. 1824, p. 4.

CORREIO Mercantil, 28 jun. 1852, p. 1.

CAVALCANTI, Nireu. O Rio de Janeiro setecentista. Rio de Janeiro: Zahar, 2014.

O DESPERTADOR, 30 jan. 1840, p. 4.

DIÁRIO do Rio de Janeiro, 17 abr. 1822, p. 51.

DIÁRIO do Rio de Janeiro, 4 fev. 1823a, p. 11.

DIÁRIO do Rio de Janeiro, 15 abr. 1823b, p. 51.

DIÁRIO do Rio de Janeiro, 15 set. 1823c, p. 48.

DIÁRIO do Rio de Janeiro, 16 nov. 1826, p. 51.

DIÁRIO do Rio de Janeiro, 11 out. 1827, p. 39.

DIÁRIO do Rio de Janeiro, 25 abr. 1828a, p. 79.

DIÁRIO do Rio de Janeiro, 14 maio 1828b, p. 51.

DIÁRIO do Rio de Janeiro, 17 mar. 1829, p. 55.

DIÁRIO do Rio de Janeiro, 12 abr. 1831, p. 22.

DIÁRIO do Rio de Janeiro, 13 abr. 1833, p. 43.

DIÁRIO do Rio de Janeiro, 10 out. 1840, p. 4. 
DIÁRIO do Rio de Janeiro, 23 maio 1846b, p. 4.

DIÁRIO do Rio de Janeiro, 24 ago. 1843, p. 4.

DIÁRIO do Rio de Janeiro, 25 ago. 1846, p. 4.

DIÁRIO do Rio de Janeiro, 28 out., 1840b, p. 1.

DIÁRIO do Rio de Janeiro, 3 out. 1857b, p. 1.

DIÁRIO do Rio de Janeiro, 30 maio 1844, p. 4.

DIÁRIO do Rio de Janeiro, 7 ago. 1851, p. 3.

DIÁRIO do Rio de Janeiro, 4 abr. 1857a, p. 4.

GAZETA do Rio de Janeiro, 13 jul. 1811, p. 6.

GAZETA do Rio de Janeiro, 26 out. 1814, p. 8.

GAZETA do Rio de Janeiro, 2 jun. 1821, p. 4.

JOSÉ, Ana Maria de São. Samba de gafieira: corpos em contato na cena social carioca. Dissertação (Mestrado em Artes Cênicas) - Universidade Federal da Bahia, Salvador, 2005.

LANGE, Francisco Curt. Os primeiros subministros musicais do Brasil para o Rio da Prata: a reciprocidade musical entre o Brasil e o Prata. A música nas ações bélicas. (De 1750 até 1855, aproximadamente). Revista de História, São Paulo, n. 112, p. 381-417, dez. 1977.

LEITE, Miriam Lifchitz Moreira. Adèle Toussaint-Samson em dose dupla. Estudos Feministas, Florianópolis, v. 12, n. 2, p. 251-253, 2004.

LEME, Mônica. E "saíram à luz" as novas coleções de polcas, modinhas, lundus, etc.: música popular e impressão musical no Rio de Janeiro (1820-1920). Tese (Doutorado em História) Universidade Federal Fluminense, Niterói, 2006.

LIMA, Evelyn Furquim Werneck. Arquitetura do espetáculo: teatros e cinemas na formação da Praça Tiradentes e da Cinelândia. Rio de Janeiro: Editora UFRJ, 2000.

MALERBA, Jurandir. Sobre o tamanho da comitiva. Acervo, Rio de Janeiro, v. 21, n. 1, p. 47-62, jan./ jun. 2008.

MARZANO, Andrea. A magia dos palcos: o teatro no Rio de Janeiro do século XIX. In: MARZANO, Andrea; MELO, Victor Andrade de (Org.). Vida divertida: histórias do lazer no Rio de Janeiro (18301930). Rio de Janeiro: Apicuri, 2010. p. 97-123.

MELO, Victor Andrade de. Esporte e lazer: conceitos, uma introdução histórica. Rio de Janeiro: Apicuri, 2010.

MELO, Victor Andrade de. Educação do corpo: bailes no Rio de Janeiro do século XIX, o olhar de Paranhos. Educação e Pesquisa, São Paulo, v. 40, n. 3, p. 751-766, jul./set. 2014.

MELO, Victor Andrade de, PERES, Fabio de Faria. A gymnastica no tempo do Império. Rio de Janeiro: 7Letras, 2014.

NEEDELL, Jeffrey D. Belle époque tropical. São Paulo: Companhia das Letras, 1993.

NEVES, Lucia Bastos Pereira das. A vida política. In: SILVA, Alberto da Costa (Coord.). História do Brasil nação (1808-2010). Rio de Janeiro: Objetiva, 2011. v. 1: Crise colonial e independência (18081830). p. $75-114$.

NORTON, Luís. A corte de Portugal no Brasil. São Paulo: Companhia Editora Nacional, 2008.

OSSONA, Paulina. A educação pela dança. São Paulo: Summus, 1988.

PINHO, Wanderley. Salões e damas no Segundo Reinado. São Paulo: Livraria Martins, 1942. 
ROQUETE, José Ignacio. Código do Bom-Tom. São Paulo: Companhia das Letras, 1997.

SCHULTZ, Kirsten. Perfeita civilização: a transferência da corte, a escravidão e o desejo de metropolizar uma capital colonial. Rio de Janeiro, 1808-1821. Tempo, Niterói, v. 12, n. 24, p. 5-27, 2008.

SCHWARCZ, L. M. Introdução. In: ROQUETE, José Ignacio. Código do Bom-Tom. São Paulo: Companhia das Letras, 1997. p. 7-32.

SCHWARCZ, Lilia Moritz. Cultura. In: SILVA, Alberto da Costa (Coord.). História do Brasil Nação (1808-2010). Rio de Janeiro: Objetiva, 2011. v. 1: Crise colonial e independência (1808-1830). p. 205248.

O SETE de Abril, 24 maio 1837, p. 4.

SILVA, Erminia. Circo-teatro: Benjamin de Oliveira e a teatralidade circense no Brasil. São Paulo: Altana, 2007.

SILVA, Maria Beatriz Nizza da. Cultura e sociedade no Rio de Janeiro (1808-1821). São Paulo: Companhia Editora Nacional, 1978.

ZAMITH, Rosa Maria. A dança da quadrilha. Rio de Janeiro: E-papers, 2011.

ZAMONER, Maristela. História da Dança de Salão no Brasil do século XIX e os irmãos Lacombe. EFDeportes.com, Buenos Aires, v. 18, n. 186, nov. 2013. Disponível em: <http://www.efdeportes. com/efd186/historia-da-danca-de-salao-irmaos-lacombe.htm>. Acesso em: 12 abr. 2016. 